\title{
The performance of different cumulus parameterization schemes in simulating the $2006 / 2007$ southern peninsular Malaysia heavy rainfall episodes
}

\author{
Wan Ahmad Ardie ${ }^{1}$, Khai Shen Sow ${ }^{1}$, Fredolin T Tangang ${ }^{1}$, Abdul Ghapor Hussin ${ }^{2}$, \\ Mastura Mahmud ${ }^{3}$ and Liew Juneng ${ }^{1, *}$ \\ ${ }^{1}$ Climate and Ocean Analysis Laboratory, Research Centre for Tropical Climate Change System (IKLIM), \\ Faculty of Science and Technology, Universiti Kebangsaan Malaysia, 43600 Bangi, Selangor, Malaysia. \\ ${ }^{2}$ Centre for Foundation Studies in Science, Universiti of Malaya, 50603 Kuala Lumpur, Malaysia. \\ ${ }^{3}$ Earth Observation Centre, Faculty of Social Sciences and Humanities, Universiti Kebangsaan Malaysia, \\ 43600 Bangi, Selangor, Malaysia. \\ *Corresponding author.e-mail: juneng@ukm.my
}

The performance of four different cumulus parameterization schemes (CPS) in the Weather Research and Forecasting (WRF) model for simulating three heavy rainfall episodes over the southern peninsular Malaysia during the winter monsoon of 2006/2007 were examined. The modelled rainfall was compared with the 3-hourly satellite observation and objectively scored using a verification technique called the acuity-fidelity. The technique is based on minimization of a cost function that is calculated from four parameters taking into account errors in distance, time, intensity, and missed events. All simulations were made for 72 hours for the three episodes starting at 1200 UTC 17 December 2006, 1200 UTC 24 December 2006 and 1200 UTC 11 January 2007, respectively. The four different CPSs used are the new Kain-Fritsch scheme (KF2), the Betts-Miller-Janjic scheme (BMJ), the Grell-Devenyi ensemble scheme (GD) and the older Kain-Fritsch scheme (KF1). While the BMJ scheme shows some success in the second and third episodes, it shows high location errors in the first episode, leading to high acuity errors. The GD, KF2 and KF1 schemes performed poorly, although both the BMJ and GD schemes simulated the observed drastic increase of rainfall at 2100 UTC 18 December 2006 during the first episode. Overall, the KF1 and KF2 schemes produced positive biases in terms of coverage, while the GD scheme showed persistent location bias, producing a scattered line of precipitation over the eastern coastline of peninsular Malaysia. Although the BMJ scheme has better results, its poor performance for the first episode suggests that suitability of CPS may be case dependent.

\section{Introduction}

The Malaysian climate is generally categorized as warm and humid, having a narrow annual range of temperature and frequent rainfall throughout the year. The rainy season is mainly between November and February, and heavy rainfall is a common feature. Despite this, extreme flood events are relatively rare. Such rare events have huge impacts on a developing nation such as Malaysia. The 2006/2007 extreme floods that occurred in the southern peninsular Malaysia is an example of a rare and extreme weather event. The loss has been estimated around USD 500 million in economy and

Keywords. Modelling; acuity-fidelity; cumulus parameterization scheme; southern peninsular Malaysia; rainfall. 
16 reported deaths (Tangang et al 2008). While poor drainage in residential areas is one of the causes of flooding, this is mainly an unfortunate administration problem. Forecasting could play an important parallel role in the prevention of future alike disasters. This emphasizes the importance of rain prediction, in particular extremely heavy rain, in this region. This requires better understanding of the development of isolated heavy precipitation. Although the process is much more complex in reality, numerical weather prediction models artificially separate the process and scale of convective precipitation from its dynamical field. This allows representation of precipitation through the use of cumulus parameterization schemes (CPS).

Despite its great potential and sophistication, numerical weather prediction (NWP) for the maritime continent still proves a great challenge to atmospheric modellers. A contributing factor to this is the complex distribution of the islands and shallow seas resulting in large variation during the diurnal cycle in this region (Chang et al 2005). Surrounded by complex topographic features, this 'maritime continent' also plays an important role globally. Latent heat release over this region interacts with global and regional scale processes; an example is the strong East Asian baroclinic system affecting the East Asian jet (Chang and Lau 1982). In a study of the sensitivity of global models systematic errors to the heating of this region, Neale and Slingo (2003) have demonstrated dry bias tendencies of the models. Equally problematic is the limited number of modelling studies. A small number of related studies over this region using PSU/NCAR MM5 model (e.g., Juneng et al 2007a, 2007b; Salimun et al 2010; Sow et al 2010) have indicated varying degrees of success in high resolution numerical simulations of tropical weather rainfall systems. The apparent lack of modelling over this region combined with poor data coverage results in limited understanding of the structure and characteristic of the relevant synoptic disturbances that influence the weather pattern of this region (Chang et al 1979). All this emphasizes the importance of further studies to enhance the understanding of the weather characteristics.
Apart from its importance to weather forecasters in general, extensive verification of NWP models in different synoptic conditions help to assess its current progress. Sensitivity studies of these models to various factors such as the various physical parameterization schemes (e.g., Kotroni and Lagouvardos 2004; Jankov et al 2007; Rakesh et al 2007, 2010; Hu et al 2010; Salimun et al 2010), initial conditions (e.g., Singh et al 2008; Rakesh et al 2009) and time step size (e.g., Xu et al 2001) help to assess its progress and suggest improvements of NWP models to the scientific community.

A sensitivity study of the WRF model to four CPSs is conducted using the Kain-Fritsch scheme (KF2; Kain 2004), Betts-Miller-Janjic scheme (BMJ; Janjic 1994, 2000), Grell-Devenyi ensemble scheme (GD; Grell and Devenyi 2002) and the old Kain-Fritsch scheme (KF1; Kain and Fritsch 1990, 1993). A simulation of the $2006 / 2007$ peninsular Malaysia heavy rainfall event is used as the case experiment. The modelled output is then objectively scored using a verification method called the acuity-fidelity, which was proposed by Marshall et al (2004) as a possible alternative to common verification approaches. Common methods used and cited in literature include the root mean square error (RMSE) and threat scores (e.g., Mahmud 2004; Mahmud and Ross 2005), also known as the critical success index (CSI; Donaldson et al 1975).

Section 2 discusses the details of the acuityfidelity technique including descriptions of the WRF model, design of the experiment, cumulus parameterization schemes and verification data. The results and the discussion are given in section 3. The whole study is finally concluded in section 4 .

\section{Data and methodology}

\subsection{Model description}

The model used in this study is the Weather Research and Forecasting (WRF) model (version 3.0.1), a mesoscale numerical weather prediction system developed at the National Center for Atmospheric Research (NCAR). Designed to serve both

Table 1. Model physics selected for this study.

\begin{tabular}{ll}
\hline Physics options & \multicolumn{1}{c}{ WRF } \\
\hline Microphysics & WRF single-moment 3-class scheme \\
Long wave radiation & (Hong et al 2004) \\
Short wave radiation & MM5 short wave (Dudhia scheme) \\
Surface layer & Monin-Obukhov similarity theory \\
Land surface & 5-layer thermal diffusion from MM5 \\
Planetary boundary layer & MRF PBL scheme (Hong and Pan 1996) \\
\hline
\end{tabular}


operational forecasting and atmospheric research needs, WRF is a limited area, non-hydrostatic primitive equation model with multiple options for various physical parameterization schemes. This study uses the Advanced Research WRF (ARW) dynamic solver. Throughout this study, all physical parameterizations (table 1) apart from the cumulus parameterization schemes (table 2) were set identical. Further general descriptions of WRF can be referred to Skamarock et al (2008).

\subsection{Design of numerical experiments}

The boundary condition used for all the simulations are the $1^{\circ} \times 1^{\circ}$ analyses data obtained from the National Center for Environmental Prediction (NCEP) Global Final Analyses (FNL). The simulation of all three episodes were performed on a nested domain with the child domain (D02) resolution at $9 \mathrm{~km}$ and parent domain (D01) resolution at $45 \mathrm{~km}$, as shown in figure 1 . Careful examination shows that all the nested simulations using the 1:5 grid ratio do not produce spurious result. The simulation for each of the three episodes was run for 72 hours starting at 1200 UTC 17 December 2006, 1200 UTC 24 December 2006 and 1200 UTC 11 January 2007, respectively (refer to table 3). An analysis of the synoptic conditions and factors affecting the weather patterns in these three episodes can be referred to Tangang et al (2008). A total of 12 simulations were conducted using four different CPSs of the WRF model; the

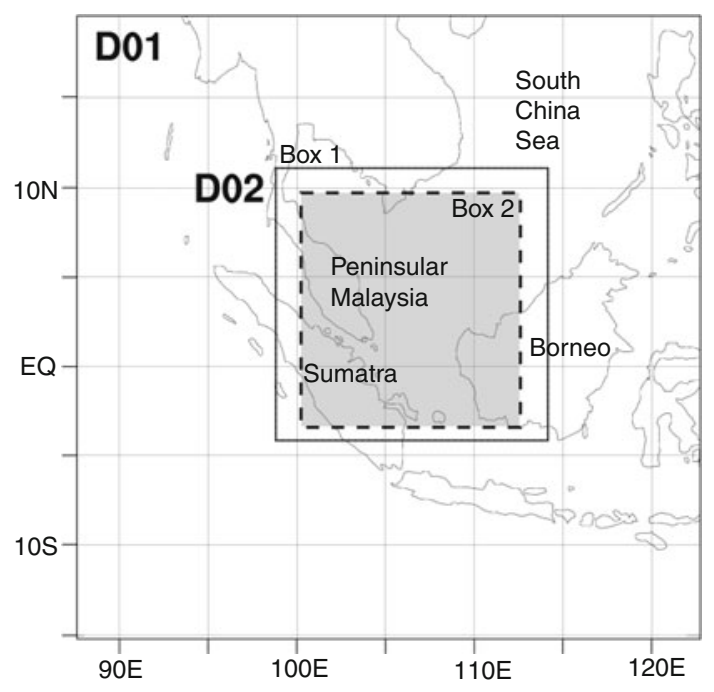

Figure 1. The nested domains used in the WRF simulation. Grid points within the child domain (D02) are used for the acuity-fidelity approach. The acuity-fidelity's candidate grid points are defined within Box $1(60 \times 59)$, and its matching target data points are defined within Box $2(52 \times$ 51) (refer to section 2.5 for details). new Kain-Fritsch scheme (KF2); the Betts-MillerJanjic scheme (BMJ); the Grell-Devenyi ensemble scheme (GD) and the old Kain-Fritsch scheme (KF1).

\subsection{Cumulus parameterization schemes}

Different CPSs have different principles in representing the cumulus convection. Table 2 shows a summary of the cumulus parameterization schemes used in this study based on its design aspects, trigger function, closure assumption, precipitation scheme and some of the improvements over its older version. The BMJ scheme is a modification of the old Betts-Miller scheme (Betts 1986; Betts and Miller 1986). Both are adjustment type schemes, where vertical profiles of temperature and humidity are adjusted until stability is achieved. There is also no cloud model in this scheme. Some of the improvements in the BMJ scheme include a deep convective profile and relaxation time that is allowed to vary depending on parameters that characterize the convective environment (Skamarock et al 2008).

The KF1 (Kain and Fritsch 1990, 1993) scheme uses simple cloud model with updrafts and downdrafts, including the effects of detrainment and entrainment. It differs from the BMJ scheme in that the KF1 uses a cloud model based on a mass flux formulation. Such CPSs are considered more physically based as it attempts to represent the cloud dynamics as well. The KF2 scheme (Kain 2004) is a more recent modification of the old KF1 scheme. Both schemes, however, are based on a mass flux formulation and attempt to remove the CAPE (convective available potential energy).

The GD scheme (Grell and Devenyi 2002) is an ensemble cumulus scheme in which multiple cumulus schemes and variants are run within each grid box. There are 144 members (Skamarock et al 2008) of the ensemble scheme and all members have different static controls and dynamic controls. The static controls are parameters that determine the cloud thermodynamic properties while dynamic control determines the amount and location of convection (Betts 1974). Each of the members triggers independently, and has different trigger requirements. The amount of precipitation changes is determined by averaging the 144 members. Like the Kain-Fritsch scheme, it is a mass-flux based scheme.

\subsection{Verification data}

The modelled precipitation rate is verified against the observed rain rate from the $3 \mathrm{~B} 42$ version 6 
Table 2. Comparison of the four cumulus parameterization schemes in terms of its trigger function, closure assumption, its precipitation scheme as well as some of its improvements on its older version.

\begin{tabular}{|c|c|c|c|c|}
\hline Scheme & Trigger function & Closure assumption & $\begin{array}{l}\text { Precipitation } \\
\text { scheme }\end{array}$ & $\begin{array}{l}\text { Modifications based on } \\
\text { older predecessor }\end{array}$ \\
\hline BMJ & $\begin{array}{l}\text { Based on an instability } \\
\text { Cloud depth }>200 \mathrm{hPa} \\
\text { Sufficient moisture above } \\
\text { cloud base }\end{array}$ & $\begin{array}{l}\text { An adjustment towards } \\
\text { an equilibrium } \\
\text { reference profile }\end{array}$ & $\begin{array}{l}\text { Adjustment scheme } \\
\text { No cloud model }\end{array}$ & $\begin{array}{l}\text { Reference profile and } \\
\text { relaxation time depends on } \\
\text { parameters that characterize } \\
\text { the environment } \\
\text { Trigger function to account } \\
\text { for higher resolution }\end{array}$ \\
\hline GD & $\begin{array}{l}\text { Trigger function varies for } \\
\text { each member but are } \\
\text { commonly based on: } \\
\text { CAPE } \\
\text { CAPE trend } \\
\text { moisture convergence }\end{array}$ & $\begin{array}{l}\text { Multi-closure, can be } \\
\text { based on: } \\
\text { CAPE } \\
\text { moisture convergence } \\
\text { low-level vertical velocity }\end{array}$ & $\begin{array}{l}\text { Cloud model with updraft } \\
\text { and downdraft fluxes } \\
\text { No lateral entrainment } \\
\text { and detrainment } \\
\text { Changes in moisture is } \\
\text { averaged over all } \\
\text { members }\end{array}$ & $\begin{array}{l}\text { Combines the strength } \\
\text { of different closure } \\
\text { assumptions in one scheme }\end{array}$ \\
\hline KF1 & $\begin{array}{l}\text { CAPE-based } \\
\text { Cloud depth }>4 \mathrm{~km}\end{array}$ & $\begin{array}{l}\text { CAPE is removed from } \\
\text { grid in convective } \\
\text { time scale }\end{array}$ & $\begin{array}{l}\text { 1D mass conservative } \\
\text { cloud model }\end{array}$ & - \\
\hline KF2 & $\begin{array}{l}\text { CAPE-based } \\
\text { Cloud depth }>3 \mathrm{~km}\end{array}$ & $\begin{array}{l}\text { CAPE is removed from } \\
\text { grid in convective } \\
\text { time scale }\end{array}$ & $\begin{array}{l}\text { 1D mass conservative } \\
\text { cloud model }\end{array}$ & $\begin{array}{l}\text { Cloud radius and cloud depth } \\
\text { threshold for deep } \\
\text { convection can vary } \\
\text { The effects of shallow } \\
\text { convection is also included }\end{array}$ \\
\hline
\end{tabular}

product of the Tropical Rainfall Measuring Mission (TRMM). The 3B42 is a combined instrument rain calibration algorithm, the purpose of which is to produce Tropical Rainfall Measuring Mission (TRMM) merged high quality (HQ)/infrared (IR) precipitation and root-mean-square precipitationerror estimates. The TRMM rain rate is available at $0.25^{\circ} \times 0.25^{\circ}$ grid resolution every 3 hours. Researchers have made use of the TRMM measurement as a high accuracy rain observation for this region (e.g., Chang et al 2005; Juneng et al 2007a, 2007b; Salimun et al 2010).

\subsection{Acuity-fidelity}

The acuity-fidelity verification is a technique designed to measure the skill noticed in subjective verification that fail to be captured in traditional objective skill metrics (Marshall et al 2004). Unlike the traditional verification techniques that associate the observation and forecast at contemporaneous space and time, the acuity-fidelity allows a best match search by minimizing the cost function calculated between the target observation and several adjacent candidate forecast datum. The cost function penalized errors in distance $\left(J_{s}\right)$, errors in time $\left(J_{t}\right)$ and errors in intensity $\left(J_{i}\right)$ together with a fourth term $\left(J_{e}\right)$ to account for missed events (Marshall et al 2004).

$$
J=J_{s}+J_{t}+J_{i}+J_{e} .
$$

The intensity is referred to 3 -h averaged precipitation rate in this study. The candidate forecast datum that produces the smallest penalty is deemed the best match and is therefore associated with the observation (Sousounis et al 2004). The following definitions determine the sensitivity of the total error result to the four components. The four components are converted to common units $(\mathrm{km})$ using the following definition:

$$
\begin{aligned}
& J_{s}=\Delta x, \\
& J_{t}=U_{e} \Delta t, \\
& J_{i}=D I \Delta I, \\
& J_{e}=f\left(J_{\text {miss }} \text { intensity regimes }\right) .
\end{aligned}
$$

The variables $\Delta x, \Delta t$, and $\Delta I$ represent absolute difference in position, time and intensity, respectively. The $U_{e}$ is the characteristics event velocity used to relate the temporal and spatial errors while the $D I$ is the distance-intensity ratio used to relate the intensity and spatial errors. $J_{\text {miss }}$ is the maximum possible value of $J_{e}$ and represents a complete miss. The intensity regimes (IR) are a list 
of intensity values that define intensity categories. The IR is a real number that represents a position within the defined ranges. For example, a value of 1.5 represents a position halfway between the 1 st and 2nd thresholds. The differences between the IR of the observation and forecast determine the value of $J_{e}$; set to zero if IR differences are $<1$, set to $J_{\text {miss }}$ if $>2$, a linear interpolation between zero and $J_{\text {miss }}$ if differences are in between 1 and 2 . Further details of this technique as well as a comparison with other techniques can be referred to Marshall et al (2004). The values for the cost function parameters were set to these values: $J_{\text {miss }}=$ $1000 \mathrm{~km}, U_{e}=36 \mathrm{~km} / \mathrm{hr}, D I=20 \mathrm{~km} / \mathrm{mm} / \mathrm{hr}$ and intensity thresholds at $0.25,2.5,15$ and $50 \mathrm{~mm}$. The evaluation of the most suitable set of parameters is not considered in this study. Based on Marshall et al (2004), the determination of the best choice of parameters is highly subjective and has little effect on differences in results.

The acuity-fidelity assesses model realism better than traditional techniques (e.g., RMSE, threat scores) due to lesser sensitivity to point-by-point errors. Mass et al (2002) discusses how a higher resolution while subjectively appears to be better, may achieve a poorer result on objective scores. This may be due to the higher number of data points with improper location and timing. Acuity is generally the accuracy of the model, and represents the model's realism or skill at detecting the spatial distribution of features such as rain. In the calculation, the observation is used as the target data where a set of forecast values are used as candidate to be matched with the target. Fidelity measures faithfulness of the model's prediction to observation. Roles are reversed, therefore the forecast is treated as the target data. This ensures that all grid points of forecast that the acuity might miss are accounted for. In this sense, the fidelity is a complement to acuity. The same cost function is then applied to candidate and target data. The acuity-fidelity scores are nonscaled positive values that measured errors between the observations and the simulations. These values are useful to make relative comparison among the simulations. As the acuity-fidelity measures error, it is negatively-oriented, therefore lower values indicate better performance.

In this study, acuity and fidelity are defined in an area with longitude/latitude from $98.7^{\circ}$ $114^{\circ} \mathrm{E} / 4.3^{\circ} \mathrm{S}-10.8^{\circ} \mathrm{N}$, with a grid dimension of $60 \times$ 59 (Box 1 in figure 1 ). The nearby $9 \times 9 \times 3$ $(i \times j \times$ time $)$ candidates are processed for each target data point. Box 2 in figure 1 contains $52 \times 51$ of these target grid points. In the acuity and fidelity computation, the modeled data is spatially aggregated to the coarser TRMM resolution. The first and the last 6 hours were omitted. This allowed the 
acuity-fidelity calculation to extract information it requires before and after the target time.

\section{Results and discussion}

\subsection{Simulation of first episode}

Based on the observed rain rate during the first episode, from 1500 UTC 19 December 2006 towards the end of the first episode, the center of precipitation was located over southern peninsular Malaysia heading towards the northern region of peninsular Malaysia. This notable movement of rain feature was mostly over land, meaning persistent precipitation over peninsular Malaysia throughout most of the first episode. At 2100 UTC 18 December (shown in figure 2a), the observed rain rate over the eastern coastline of peninsular Malaysia reaches up to $39 \mathrm{~mm} / \mathrm{hr}$, which is the maximum rain rate over peninsular Malaysia in the first episode. This is an increase of $31 \mathrm{~mm} / \mathrm{hr}$ in 3 hours, mainly contributing to the flooding of the first episode.

The simulation using the BMJ scheme also reached its maximum at the same period of 2100 UTC 18 December 2006. The model output showed the precipitation before this particular period concentrating over the South China Sea before propagating towards the eastern side of the peninsular achieving a maximum of $\sim 50 \mathrm{~mm} / \mathrm{hr}$. Towards the end of the simulation period, the observed propagation of precipitation from southern to northern peninsular is represented as a notable increase of precipitation over northeastern peninsular and southern Thailand.

The GD scheme produces a line of precipitation (e.g., figure 2a) persisting $\sim 28$ hours starting 2100 UTC 17 December 2006. The maximum of this feature also occurs on 2100 UTC 18 December $(\sim 29 \mathrm{~mm} / \mathrm{hr})$. The location of this maximum, however, is slightly off-shore on the eastern side of the peninsular Malaysia. This location bias is persistent throughout the episode. There is no distinctive propagation of precipitation from southern to northern region of the land as observed but a notable increase of precipitation over northeastern peninsular Malaysia and lower Thailand. The GD scheme produces widespread features although persistent precipitation $>6 \mathrm{~mm} / \mathrm{hr}$ is notably concentrated over the eastern side of peninsular Malaysia (e.g., figure 2a). On the other hand, both the KF1 and KF2 schemes failed to reproduce the observed drastic increase at 2100 UTC 18 December. Both schemes produced relatively average and widespread precipitation leading to overall bad score. Figure $3(\mathrm{~b})$, which is the accumulated (a)
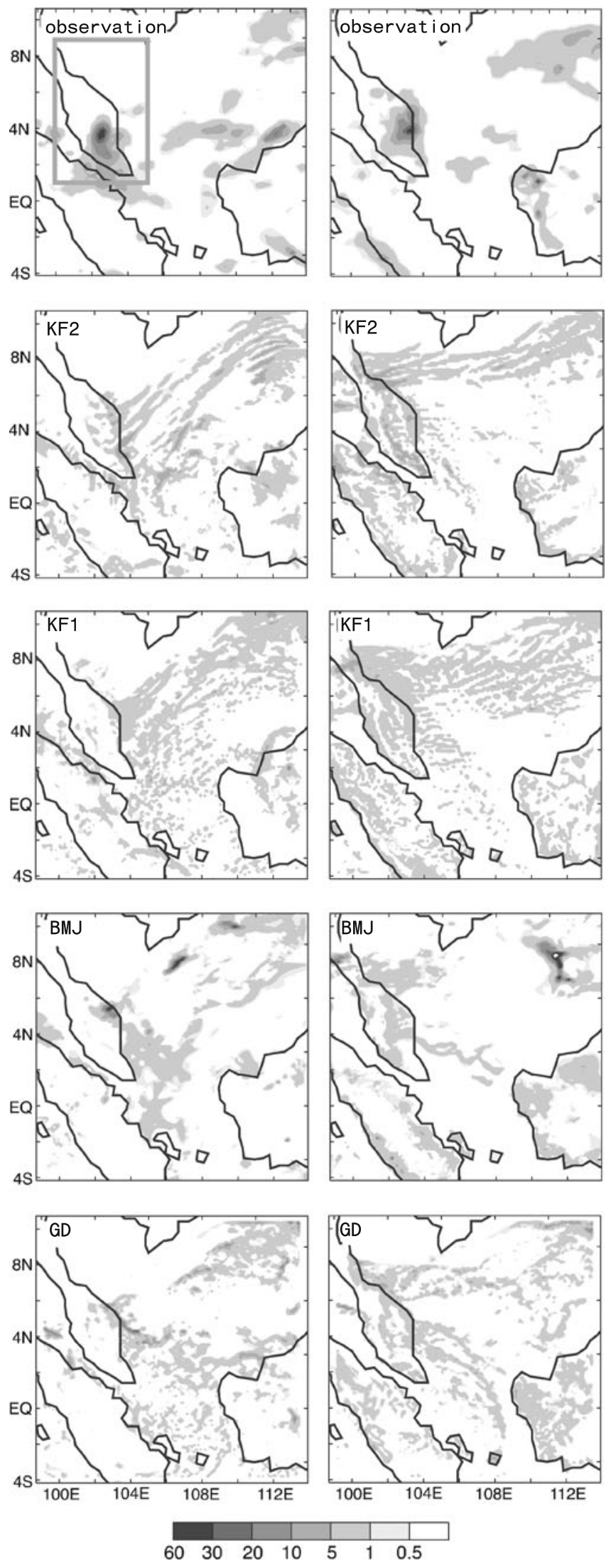

Figure 2. Observed and modelled rain rate $(\mathrm{mm} / \mathrm{hr})$ from four different cumulus parameterization schemes for the times (a) 2100 UTC 18 December and (b) 0900 UTC 20 December 2006 of the first episode. 
maximum rainfall shows the KF1 and KF2 tendency to quantitatively underestimate the precipitation. Figure $3(\mathrm{~b})$ is calculated within a region of $100.0^{\circ}-105.0^{\circ} \mathrm{E} / 1.2^{\circ} \mathrm{S}-9.0^{\circ} \mathrm{N}$ (refer to outline in figure $2 \mathrm{a}$ ).

The line graph in figure 3(a) shows the maximum rain rate of the observation, $\mathrm{BMJ}, \mathrm{GD}, \mathrm{KF} 1$ and KF2 schemes, derived from the same region of figure 3(b). This illustrates how both BMJ and GD schemes successfully simulated the drastic increase in rain rate, while both $\mathrm{KF} 1$ and $\mathrm{KF} 2$ show poorer performance. However, all four schemes did not capture the spatial features well. The BMJ scheme produced significant location errors despite clearly recognizable features, such as in figure 2. Hence, the BMJ scheme achieves relatively higher acuity error in the first episode, compared to the second and third episodes (figure 4a). The fidelity score, however, indicates that towards the end of the verification period, the fidelity or 'faithfulness' of the BMJ scheme is better than the other three schemes (figure $4 b$ ).

\subsection{Simulation of second episode}

In the second episode, there is a relatively drastic increase of observed rain rate $(\sim 20 \mathrm{~mm} / \mathrm{hr}$ within 6 hours) at 2100 UTC 25 December 2006
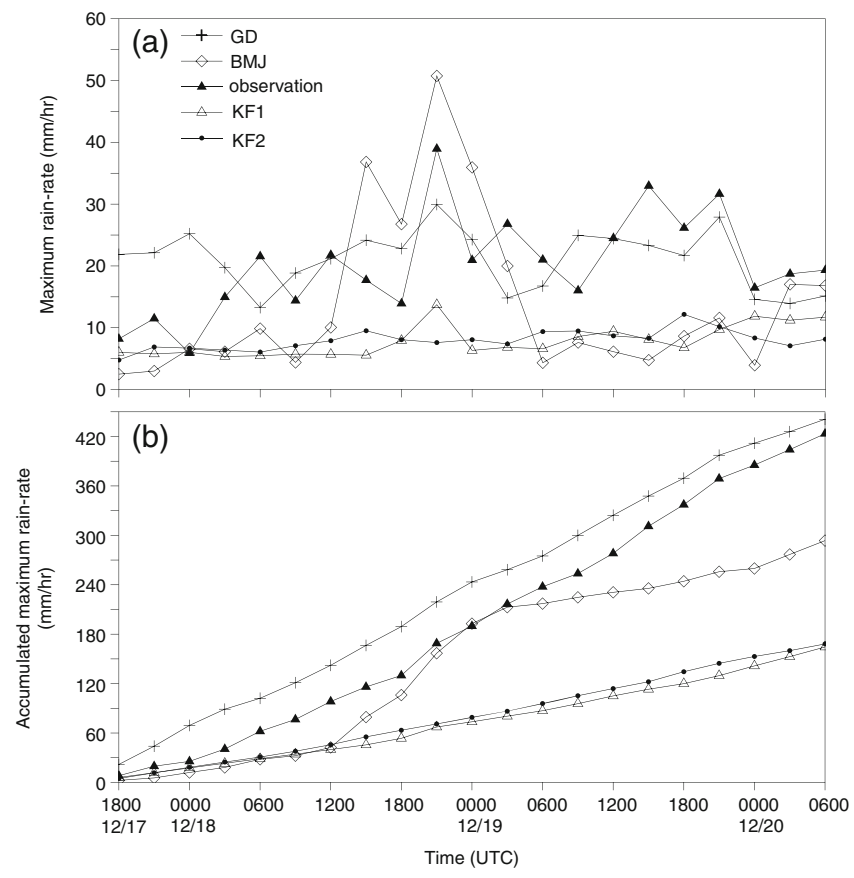

Figure 3. Comparison of (a) instantaneous maximum rain rate and (b) the associated accumulated maximum rain rate between the observation and the simulations output during the first episode. The values are calculated from the grids within the rectangular region shown in figure $2(\mathrm{a})$.
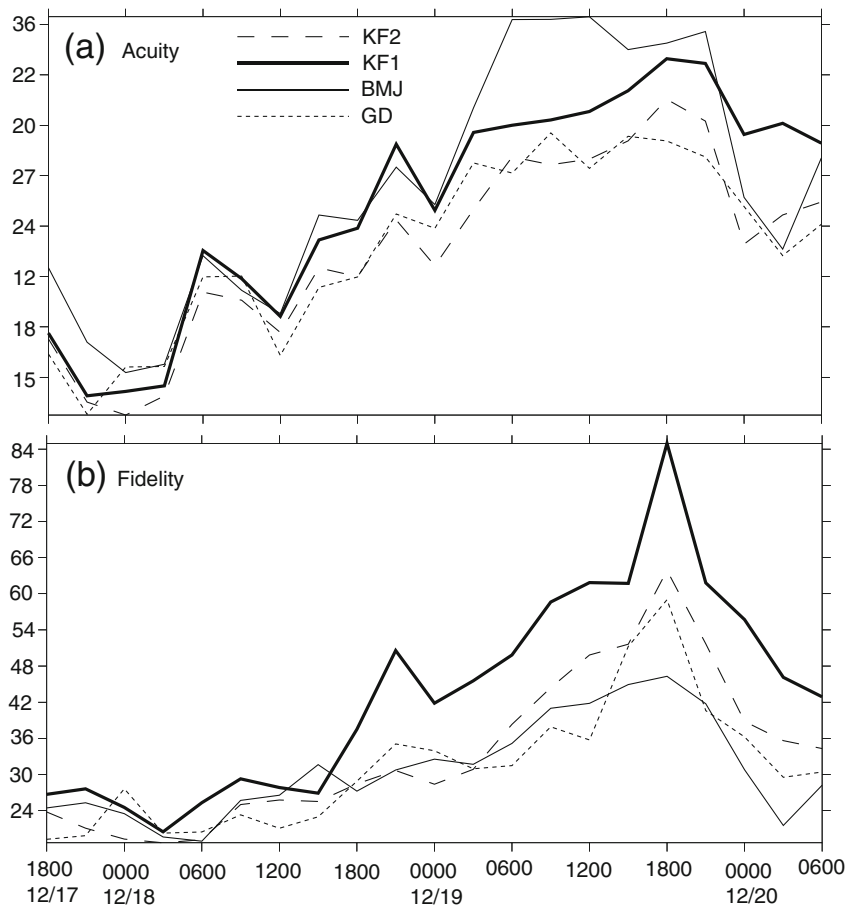

Figure 4. (a) Acuity and (b) fidelity score of the first episode between 1800 UTC 17 December and 0600 UTC 20 December 2006 for the four different cumulus parameterization schemes.

(figure 5a) over southern peninsular Malaysia (Johor state), the maximum rain rate recorded reached $27 \mathrm{~mm} / \mathrm{hr}$. This is less severe than the first episode, but nonetheless contributed greatly to the increasing floods over southern peninsular in the second episode. Throughout the second episode, there is a notable period of intense rain feature persisting between 1500 UTC 25 December and 1500 UTC 26 December over the region. Later between 1800 UTC 26 December and 0000 UTC 27 December, maximum rain rate is located off-shore on the eastern side of Singapore. Some of the schemes managed to produce this off-shore feature with varying success.

In this episode, the BMJ scheme simulated the intense rain feature over southern peninsular Malaysia between 2300 UTC 24 December and 1000 UTC 26 December, 16 hours earlier as well as the intense feature over Singapore between 2100 UTC 26 December and 0400 UTC 27 December. Similarly to the first episode, the GD scheme produces a scattered line of precipitation that persistently remained off-shore throughout this episode. On the other hand, both KF1 and KF2 schemes failed at representing these features. Both schemes produced similarly widespread distribution of precipitation within $2-7 \mathrm{~mm} / \mathrm{hr}$, although the KF1 scheme produces much more widespread light precipitation $(<2 \mathrm{~mm} / \mathrm{hr})$. This caused the acuity-fidelity of the KF1 scheme to be 
(a)
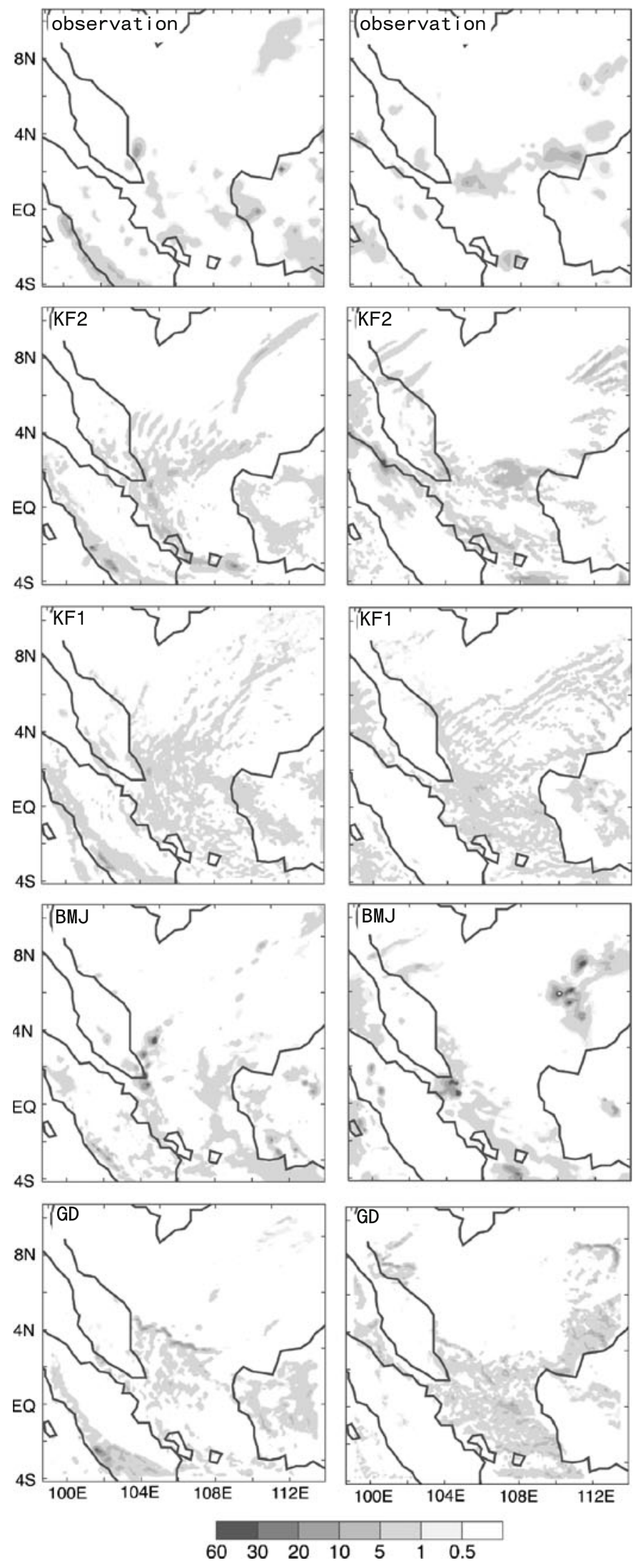

Figure 5. Observed and modelled rain rate $(\mathrm{mm} / \mathrm{hr})$ from four different cumulus parameterization schemes for the times (a) 1200 UTC 25 December and (b) 0000 UTC 27 December 2006 of the second episode.

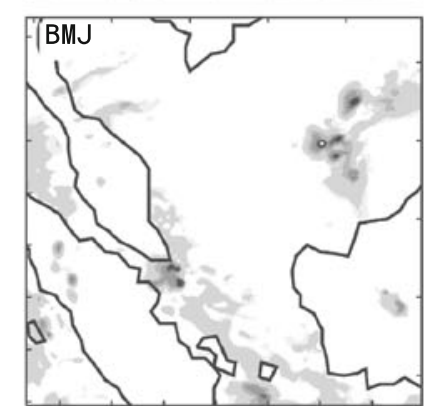

the highest throughout the second episode (figure $6 \mathrm{a}$ and $\mathrm{b})$.

\subsection{Simulation of third episode}

The maximum observed rain rate in this episode occurred at 1800 UTC 12 January 2007 (figure 7a), reaching up to $44 \mathrm{~mm} / \mathrm{hr}$, an increase of $40 \mathrm{~mm} / \mathrm{hr}$ in 3 hours. In comparison to the first two episodes, the observation shows intense and relatively persistent precipitation over the land region of the southern peninsular Malaysia.

All four schemes failed to reproduce the drastic increase in rain rate at 1800 UTC 12 December 2006. In the third episode, the BMJ scheme shows a more realistic location of precipitation. This is most evident at 1800 UTC 13 January 2007 (figure 7b). At this period, both KF1 and KF2 schemes produced similar scattered features, while the GD shows the same location bias over eastern coastline. Additionally, from the beginning of the verification period of the third episode, the BMJ scheme achieves persistent best scores of acuity and fidelity (figure 8a and b). The BMJ produces precipitation mostly over northern Karimata Strait, with some periods of heavy rainfall over southern peninsular Malaysia. Compared to the observation, this is lesser rainfall over the land region. Generally, the BMJ scheme has the least location error in the
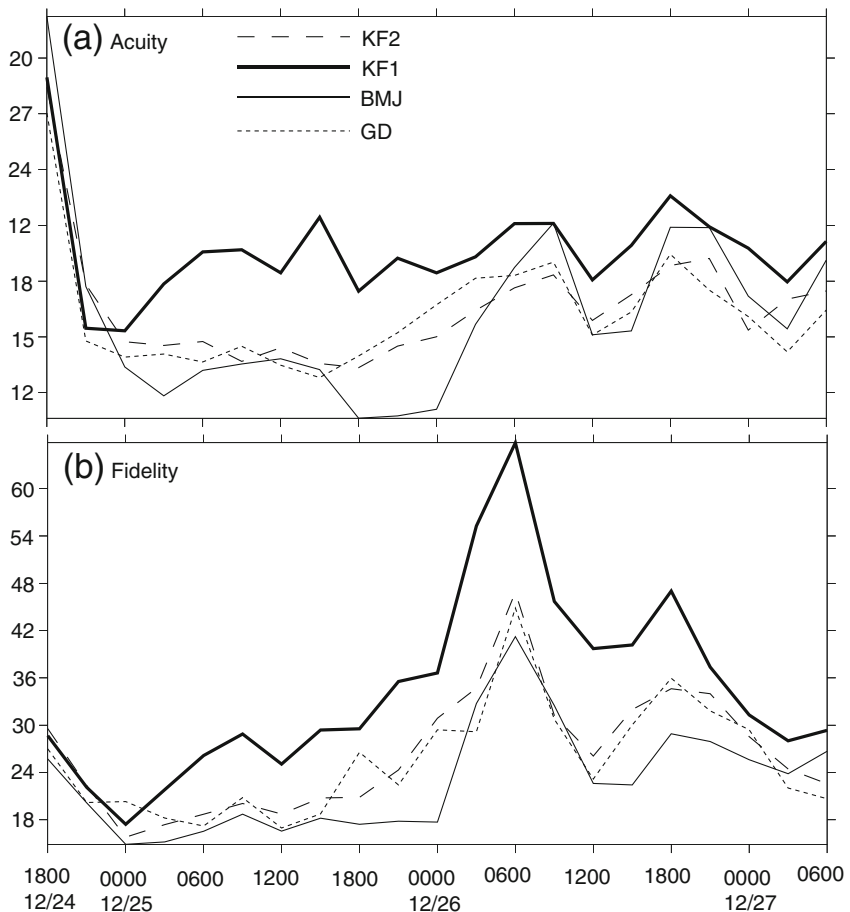

Figure 6. (a) Acuity and (b) fidelity score of the second episode between 1800 UTC 24 December and 0600 UTC 27 December 2006 for the four different cumulus parameterization schemes. 
(a)
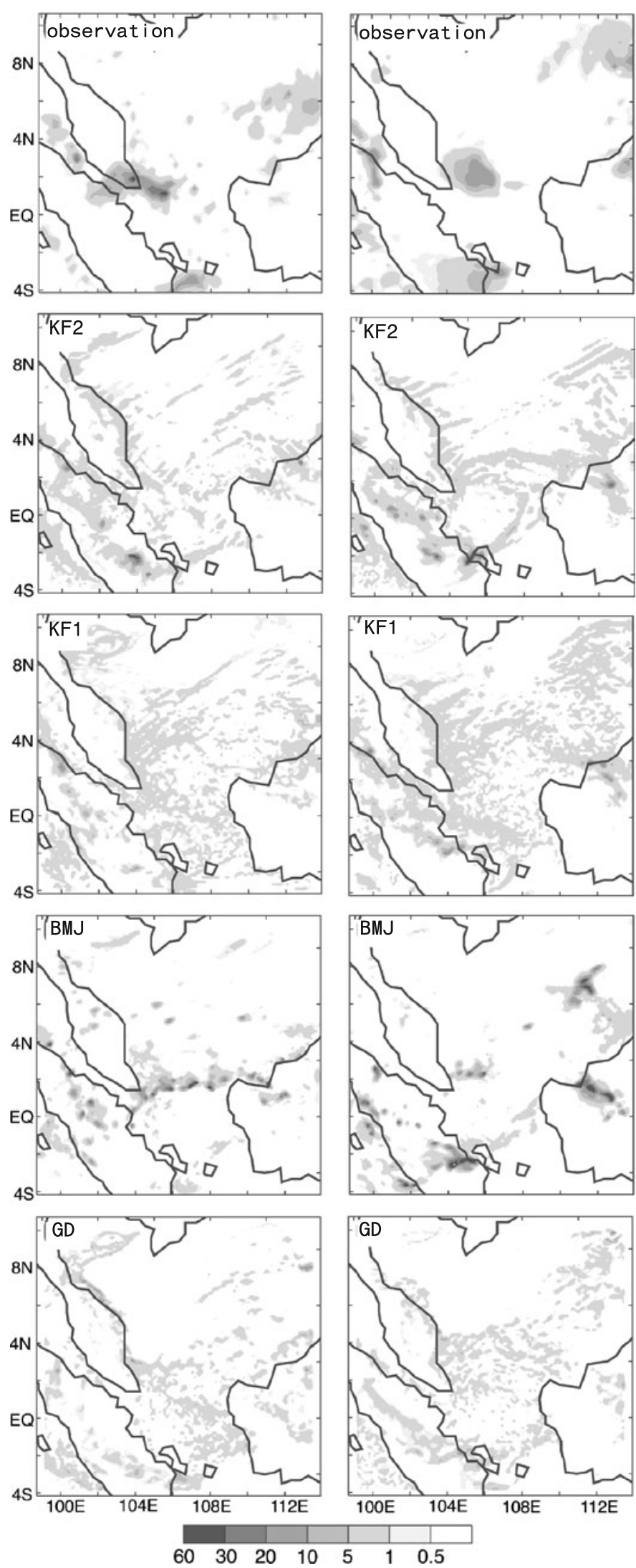

Figure 7. Observed and modelled rain rate $(\mathrm{mm} / \mathrm{hr})$ from four different cumulus parameterization schemes for the time (a) 1800 UTC 12 January and (b) 1800 UTC 13 January 2007 of the third episode.
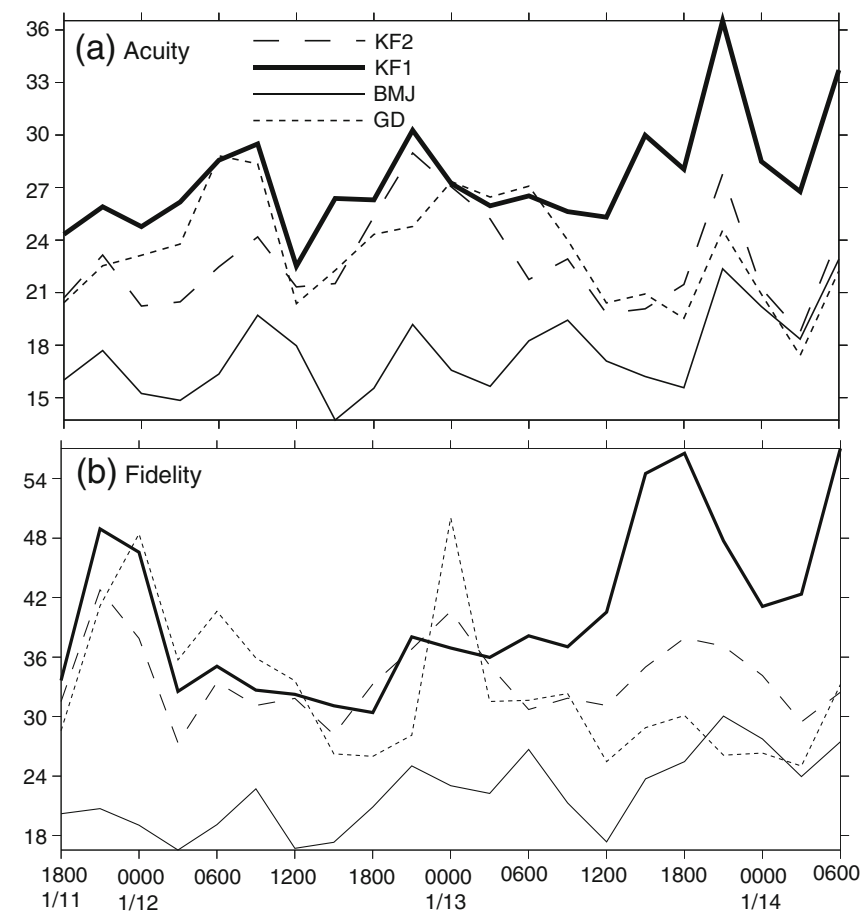

Figure 8. (a) Acuity and (b) fidelity score of the third episode between 1800 UTC 11 January and 0600 UTC 14 January 2007 for the four different cumulus parameterization schemes.

third episode, but failed to simulate precipitation over the land.

\section{Conclusion}

Three days simulation is conducted for three separate episodes using the WRF model. Objective scores using acuity-fidelity are used to verify the model output. Overall, the BMJ scheme successfully simulated the spatial features, although produced high location errors in the first episode. The KF1, KF2 and GD schemes performed poorly, failing to simulate the relevant spatial features. However, the first episode shows that both the BMJ and GD schemes simulated the observed drastic increase at 2100 UTC 18 December 2006. Generally, the KF1 and KF2 schemes produced positive biases in terms of coverage, while the GD scheme shows a persistent location bias. The relative performance of these four schemes is also shown in the acuity-fidelity score, with larger differences in the second and third episodes. The acuity-fidelity score at 2100 UTC 18 December 2006 shows that high values of intensity do not influence these scores, showing some reliability for objectively scoring spatial errors. In conclusion, based on subjective verification and the objective scores, the performance of the four schemes is highly casedependent and the performance of the better BMJ scheme cannot be generalized for all three episodes. 


\section{Acknowledgement}

The authors are grateful to the Malaysian Government as this research was funded by The Malaysian Government Science Fund Grant No. 04-01-02SF0437.

\section{References}

Betts A K 1974 The scientific basis and objectives of the U.S. subprogram for the GATE; Bull. Am. Meteorol. Soc. 55 304-313.

Betts A K 1986 A new convective adjustment scheme. Part I: Observational and theoretical basis; Quart. J. Roy. Meteorol. Soc. 112 677-691.

Betts A K and Miller M J 1986 A new convective adjustment scheme. Part II: Single column tests using GATE wave, BOMEX, ATEX, and Artic air-mass data sets; Quart. J. Roy. Meteorol. Soc. 112(473) 693-709.

Chang C P, Erickson J E and Lau K M 1979 Northeasterly cold surges and near-equatorial disturbances over the winter MONEX area during December 1974. Part I: Synoptic aspects; Mon. Weather Rev. 107 812-829.

Chang C P and Lau K M 1982 Short-term planetaryscale interactions over the tropics and midlatitude during northern winter. Part I: Contrasts between active and inactive periods; Mon. Weather Rev. 110 933-946.

Chang C P, Wang Z, McBride J and Liu C H 2005 Annual cycle of southeast Asia - Maritime continent rainfall and the asymmetric monsoon transition; J. Climate $\mathbf{1 8}$ $287-301$.

Donaldson R J, Dyer R M and Kraus M J 1975 An objective evaluator of techniques for predicting severe weather events, Preprints, 9th Conf. on Severe Local Storms, Norman, OK, Amer. Meteor. Soc., Boston, pp. 321-326.

Grell G A and Devenyi D 2002 A generalized approach to parameterizing convection combining ensemble and data assimilation techniques; Geophys. Res. Lett. 29(14), doi: 10.1029/2002GL015311.

Hong S Y, Dudhia J and Chen S H 2004 A revised approach to ice microphysical processes for the bulk parameterization of clouds and precipitation; Mon. Weather Rev. 132(1) 103-120.

Hong S Y and Pan H L 1996 Nonlocal boundary layer vertical diffusion in a medium-range forecast model; Mon. Weather Rev. 124 2322-2339.

$\mathrm{Hu}$ X M, Nielsen-Gammon J W and Zhang F 2010 Evaluation of three planetary boundary layer schemes in the WRF model; J. Appl. Meteor. Climatol. 49 1831-1844.

Janjic Z I 1994 The step-mountain eta coordinate model: Further developments of the convection, viscous sublayer and turbulence closure schemes; Mon. Weather Rev 122 927-945.

Janjic Z I 2000 Comments on "Development and evaluation of a convection scheme for use in climate models"; J. Atmos. Sci. 573686.

Jankov I, Gallus Jr W A, Segal M and Koch S E 2007 Influence of initial conditions on the WRF-ARW model QPF response to physical parameterization changes; Weather Forecast 22(3) 501-509.

Juneng L, Tangang F T and Reason C J C 2007a Numerical case study of an extreme rainfall event during 9-11 December 2004 over the east coast peninsular Malaysia; Meteorol. Atmos. Phys. 98(1-2) 89-98.

Juneng L, Tangang F T, Reason C J C, Moten S and Hassan W A W 2007b Simulation of tropical cyclone
Vamei (2001) using the PSU/NCAR MM5 model; Meteorol. Atmos. Phys. 97(1-4) 273-290.

Kain J S 2004 The Kain-Fritsch convective parameterization: An update; J. Appl. Meteorol. 43 170-181.

Kain J S and Fritsch J M 1990 A one-dimensional entraining/detraining plume model and its application in convective parameterization; J. Atmos. Sci. 47(23) 2784-2802.

Kain J S and Fritsch J M 1993 Convective parameterization for mesoscale models: The Kain-Fritsch scheme. The representation of cumulus convection in numerical models; Meteor. Monogr. Amer. Meteor. Soc. 46 165-170.

Kotroni V and Lagouvardos K 2004 Evaluation of MM5 high-resolution real-time forecasts over the urban area of Athens, Greece; J. Appl. Meteor. 43 1666-1678.

Mahmud M 2004 Skill of a superensemble forecast over equatorial Southeast Asia; Int. J. Climatol. 24 19631972.

Mahmud M and Ross R 2005 Precipitation assessment of the Florida State University Superensemble forecast over Southeast Asia; Meteorological Applications 12 $177-186$.

Marshall S F, Sousounis $\mathrm{P}$ J and Hutchinson $\mathrm{T}$ A 2004 Verifying mesoscale model precipitation forecasts using an acuity-fidelity approach, Preprints, 20th Conf. on Weather Analysis and Forecasting, Seattle, Amer. Meteor. Soc. J13.3.

Mass C F, Ovens D, Westrick K J and Colle B A 2002 Does increasing horizontal resolution produce better forecasts? The results of two years of real-time numerical weather prediction in the Pacific Northwest; Bull. Am. Meteorol. Soc. 83 407-430.

Neale R B and Slingo J M 2003 The maritime continent and its role in the global climate: A GCM study; J. Climate 16 834-848.

Rakesh V, Singh R and Joshi P C 2010 Evaluation of short-range forecasts from a mesoscale model over the Indian region during Monsoon 2006; Pure Appl. Geophys., doi: 10.1007/s00024-010-0153-6.

Rakesh V, Singh R, Pal P K and Joshi P C 2007 Sensitivity of mesoscale model forecast during a satellite launch to different cumulus parameterization schemes in MM5; Pure Appl. Geophys. 164(8-9) 1617-1637.

Rakesh V, Singh R, Yuliya D, Pal P K and Joshi P C 2009 Impact of variational assimilation of MODIS thermodynamic profiles in the simulation of western disturbance; Int. J. Remote Sens. 30(18) 4867-4887.

Salimun E, Tangang F and Juneng L 2010 Simulation of heavy precipitation episode over eastern Peninsular Malaysia using MM5: Sensitivity to cumulus parameterization schemes; Meteorol. Atmos. Phys. 107 33-49.

Singh R, Pal P K, Kishtawal C M and Joshi P C 2008 The impact of variational assimilation of SSM/I and QuikSCAT satellite observations on the numerical simulation of Indian Ocean tropical cyclone; Weather Forecast 23 460-476.

Skamarock W C, Klemp J B, Dudhia J, Gill D O, Barker D M, Michael G D, Huang X Y, Wang W and Powers J G 2008 A description of the Advanced Research WRF Version 3. NCAR Tech Notes-475+STR.

Sousounis P J, Hutchinson T A and Marshall S F 2004 A comparison of MM5, WRF, RUC, and ETA performance for great plains heavy precipitation events during the Spring of 2003; Preprints, 20th Conf. on Weather Analysis and Forecasting, Seattle, Amer. Meteor. Soc., J24.6.

Sow K S, Juneng L, Tangang F T, Hussin A G and Mahmud M 2010 Numerical simulation of a severe late afternoon 
thunderstorm over Peninsular Malaysia; Atmos. Res., doi: $10.1016 /$ j.atmosres.2010.10.014.

Tangang F T, Juneng L, Salimun E, Vinayachandran P N, Seng Y P, Reason C J C, Behera S K and Yasunari $\mathrm{T} 2008$ On the roles of the northeast cold surge, the Borneo vortex, the Madden-Julian Oscillation and the
Indian Ocean Dipole during the extreme 2006/2007 flood in southern Peninsular Malaysia; Geophys. Res. Lett. 35 L14S07.

Xu M, Bao J W, Warner T T and Stensrud D J 2001 Effect of time step size in MM5 simulations of a mesoscale convective system; Mon. Weather Rev. 129 502-516. 